NIST GCR 18-016

\title{
User Instructions and Technical Details for 500 mm GHP Simulation Programs
}

\author{
William C. Thomas \\ Virginia Polytechnic Institute and State University \\ Blacksburg, Virginia 24061, USA
}

This publication is available free of charge from:

https://doi.org/10.6028/NIST.GCR.18-016

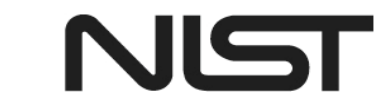

National Institute of Standards and Technology U.S. Department of Commerce 


\title{
User Instructions and Technical Details for $\mathbf{5 0 0}$ mm GHP Simulation Programs
}

\author{
Prepared for \\ U.S. Department of Commerce \\ Engineering Laboratory \\ National Institute of Standards and Technology \\ Gaithersburg, MD 20899-8632
}

By

William C. Thomas

Virginia Polytechnic Institute and State University

Blacksburg, Virginia 24061, USA

This publication is available free of charge from:

https://doi.org/10.6028/NIST.GCR.18-016

July 2018

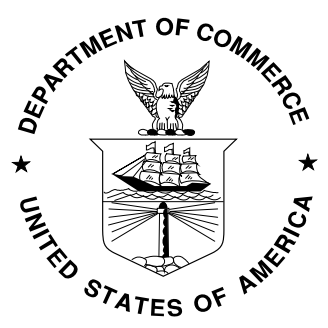

U.S. Department of Commerce Wilbur L. Ross, Jr., Secretary

National Institute of Standards and Technology Walter Copan, NIST Director and Undersecretary of Commerce for Standards and Technology 


\section{Disclaimer}

This publication was produced as part of grant 60NAN8909115 from the National Institute of Standards and Technology. The contents of this publication do not necessarily reflect the views or policies of the National Institute of Standards and Technology or the US Government. 


\begin{abstract}
This report is a supplement to the paper published as "Transient Thermal Response of an Extended Temperature Range 500-mm diameter Guarded Hot-plate Apparatus" by Thomas and Zarr (2018) [1], hereafter referred to as the "paper." The paper emphasizes the use of a mathematical model based on interconnected aggregated-capacity subcomponents to determine controller settings for power supplied to various embedded heating elements.

This report contains additional detailed information on aspects of the model that is specific to using LabVIEW ${ }^{1}$ software for simulation computations adapted to this guarded hot-plate apparatus. The report refers to equations and figures by their numbers as listed in the paper. Equations specific to this report are labeled with letters to distinguish from references to items in the paper. The purpose of the report is to assist users in correcting, modifying, or extending the mathematical model by providing additional details to facilitate "reading" the software. Specifically, the report includes heat transfer relationships used, component properties such as mass, and methods for evaluating thermal conductances along with typical values.
\end{abstract}

\title{
Key words
}

building technology; guarded hot plate; mathematical simulation; PID; temperature control; thermal conductivity; thermal response.

\footnotetext{
${ }^{1}$ The full description of the procedures used in this report requires the identification of certain commercial products and their suppliers. The inclusion of such information should in no way be construed as indicating that such products or suppliers are endorsed by NIST or are recommended by NIST or that they are necessarily the best materials or suppliers for the purposes described.
} 


\section{Table of Contents}

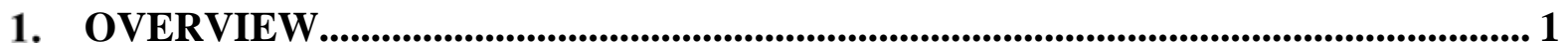

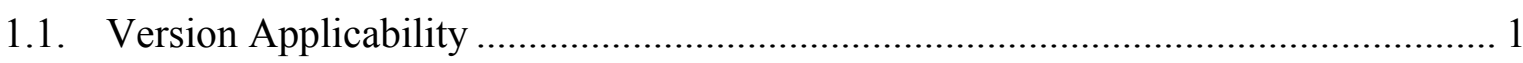

1.2. Accessing Input (Test Conditions), Output, and Debugging Information .................. 2

1.2.1. Input $\mathrm{Tab}$

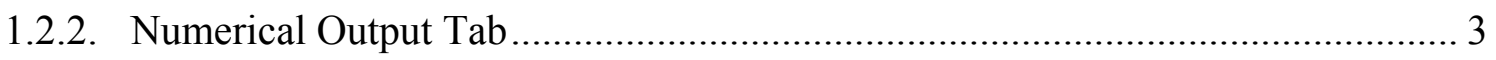

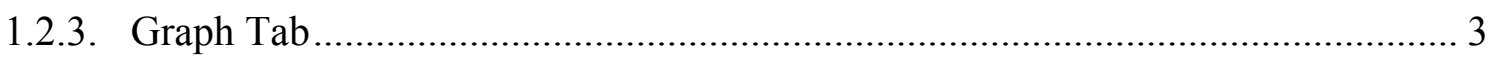

1.3. Suggestions for Deriving Satisfactory Controller Gain Settings................................. 3

1.4. LabVIEW Program Organization and Features ………….................................... 5

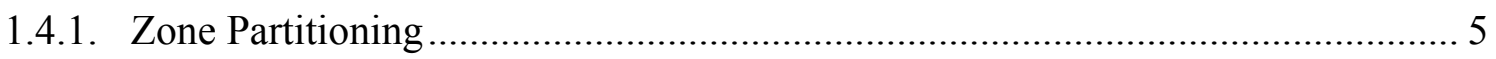

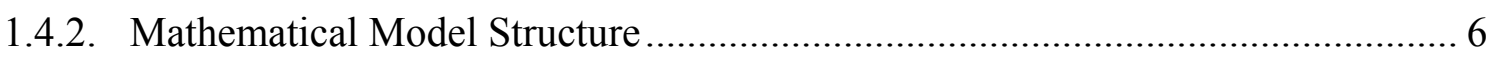

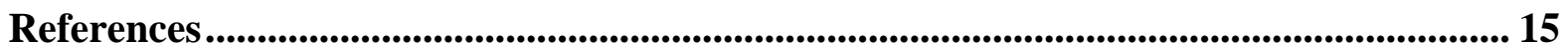

\section{List of Tables}

Table 1. Component masses and heater designations........................................................... 7

Table 2. Description, evaluation basis, and typical values of conductances. ......................... 13

Table 3. Heated element power supplies. ........................................................................... 15

\section{List of Figures}

Fig. 1. Subroutine hierarchy shown for version "hp5_12"; for other versions replace the '12' with '11' or '15'. Version "hp5_15" has one additional subroutine, SubVI Cxhspcl under CF. 


\section{Glossary}

\begin{tabular}{|c|c|c|}
\hline Symbol & Units & Description \\
\hline$A$ & $\mathrm{~m}^{2}$ & area \\
\hline$A_{\mathrm{x}}$ & $\mathrm{m}^{2}$ & cross-sectional area \\
\hline$C_{\mathrm{f}}$ & $\mathrm{W} / \mathrm{K}$ & thermal conductance \\
\hline$d, D$ & $\mathrm{~m}$ & diameter \\
\hline$g$ & $\mathrm{~m} / \mathrm{s}^{2}$ & gravitational acceleration \\
\hline$G r_{\mathrm{L}}$ & & Grashof number based on characteristic length $L$ \\
\hline$h_{\mathrm{v}}$ & $\mathrm{W} / \mathrm{K} \cdot \mathrm{m}^{2}$ & convection conductance, component surface to ambient chamber gas \\
\hline$h_{\mathrm{r}}$ & $\mathrm{W} / \mathrm{K} \cdot \mathrm{m}^{2}$ & radiation conductance, component surface to ambient \\
\hline$k$ & $\mathrm{~W} / \mathrm{K} \cdot \mathrm{m}$ & thermal conductivity \\
\hline$L$ & $\mathrm{~m}$ & fin parameter, $\sqrt{h_{v} P /\left(k A_{x}\right)}$ \\
\hline$m$ & $\mathrm{~kg}$ & mass \\
\hline$(m C)$ & $\mathrm{J} / \mathrm{K}$ & thermal capacity property \\
\hline$P$ & $\mathrm{~m}$ & perimeter \\
\hline $\operatorname{Pr}$ & & Prandtl number ambient gas \\
\hline$N u_{\mathrm{L}}$ & & Nusselt number based on characteristic length $L$ \\
\hline$q_{\mathrm{r}}$ & W & radiation heat transfer rate \\
\hline$q_{\mathrm{v}}$ & W & convection heat transfer rate \\
\hline$r$ & $\mathrm{~m}$ & radial coordinate \\
\hline$R a_{\mathrm{L}}$ & & Raleigh number based on characteristic length $L$ \\
\hline$S_{\mathrm{k}}$ & $\mathrm{m}$ & conduction shape factor, $1 / \int d r / A(r)$ \\
\hline$t$ & S & time \\
\hline$T$ & $\mathrm{~K}$ & temperature \\
\hline$U A_{\mathrm{s}}$ & $\mathrm{W} / \mathrm{K}$ & surface conductance \\
\hline$\Delta T$ & & temperature difference \\
\hline$v$ & $\mathrm{~m}^{2} / \mathrm{s}$ & kinematic viscosity \\
\hline$\varepsilon_{\mathrm{s}}$ & & surface emittance \\
\hline$\sigma$ & $\mathrm{W} / \mathrm{K}^{4} \cdot \mathrm{m}^{2}$ & Stefan-Boltzmann constant \\
\hline
\end{tabular}

Additional subscripts

$\mathrm{a}, \mathrm{b}, \mathrm{L} \quad$ refers to ambient gas (air), fin base or tip

g ambient gas

i, o inside, outside diameter

s surface

sp set point temperature

xh block heat exchanger 


\section{OVERVIEW}

The purpose of the mathematical model and simulations for the hot-plate apparatus is to derive sets of satisfactory controller gain settings for arbitrary operating conditions and various test insulation specimens. These simulations predict the thermal response of the actual apparatus using derived settings but do not otherwise interface with the apparatus.

As described and defined in the paper, the incremental form of the control algorithm is implemented. Consequently, the gains denoted integral, proportional, and (first) derivative in the traditional positional algorithm become proportional, first derivative, and second derivative respectively for incremental control. The effects of second-derivative control were determined to be negligibly small and unneeded, thus reducing the required number of gain parameters to be determined.

The method implements the following general approach: use initial guesses for the gain settings for test conditions of interest, simulate the thermal response and control using the applicable program, examine the predicted results, manually refine selected gain settings, and rerun the simulation until satisfactory performance is achieved. The gain parameters thus derived are then directly implemented on the actual apparatus. Some additional guidelines for conducting this tuning procedure are included below.

The simulations are in LabVIEW (LV) 8.6 using graphical dataflow programming in a General Design Pattern structure. The structures comprise a main program (Virtual Instrument, or VI) with layered subroutines (subVIs) for tractable block diagrams and more efficient use of common blocks of code. Arrays and matrices are used extensively for organizing variables and parameters, such as thermal conductances and equation coefficients, and passing parameters between the main and subVIs. Built-in functions are used for matrix manipulations and solving systems of algebraic equations.

\subsection{Version Applicability}

All versions simulate symmetrical (two-sided) operation of the hot-plate apparatus. Input information and predicted results for symmetrical components are shown for just one side, thus effectively reducing the number of controllers in the model from 16 to 10. As noted in Sec. 1, only proportional and derivative gains are needed for each controller, thus the required 'set' of gains is reduced from 48 to 20 values.

The three main LV programs are denoted and used as follows:

- "hp511_v1.vi" simulates the apparatus with coolant flow (whatever replaces the original ethanol) through the block heat exchanger as well as the spiral fin plate and edge guard cooling rings. The block exchanger is assumed to be at the temperature of the coolant. There are 11 other "nodal" temperatures simulated. This version applies with or without water flow in the jackets.

- "hp512_v1.vi" simulates operation with the heat exchanger disconnected and coolant flow through the spiral fin (SF) plate and edge-guard (EG) cooling rings. (This operating mode is the present case (in 2018) and likely to continue indefinitely for testing at moderately high hot-plate temperatures where coolant flow through the block heat exchanger is not needed). The temperature of the block exchanger "floats" and thus comprises an additional node to simulate for a total of 12. This version applies with or without water flow in the jackets. 
- "hp515_v1" simulates operation with water flow in the cooling jackets and no coolant flow through either the block exchanger, SF plate, or the EG cooling rings. These components are assumed to be dry. This operation is for testing at higher temperatures where coolant flow through the spiral plates, EG rings (and block heat exchanger) would likely not be useful. In addition to that of the block exchanger, temperatures of the SF plates, EG cooling rings and the coolant tube clamps, "float" and comprise 3 additional subcomponents to simulate for a total of 15 nodes.

\subsection{Accessing Input (Test Conditions), Output, and Debugging Information}

The programs use Tab Control to show separately the required input information, predicted numerical and graphical results, and intermediate calculated values useful for debugging and validation of models. Self-evident symbols and standard SI units are used for all values.

\subsubsection{Input Tab}

The initial value for Run Time is a guess of how long the apparatus takes to achieve quasisteady-state conditions. It is based on the test insulation specimen thermal conductivity, density, and thickness and updated as simulations proceed. The Control Sample Interval is that used in the actual apparatus, which is $60 \mathrm{~s}$ (default). The Calculation Step time refers to that used in the finite-difference solution of the differential equations for temperature responses. The time step should be the Control Sample Interval divided by a positive integer (60 s default).

The Chamber Air Temperature is an estimate of the average inside temperature during the run. (This value and the chamber pressure $\left(P_{\mathrm{v}}\right)$ are used primarily to evaluate natural convection parameters.) With coolant flow, the SF plate and EG cooling ring temperatures are taken as the coolant bath temperature. With no coolant flow, the temperatures of the water jackets are taken as the temperature of the water bath.

Since the temperature of the heater plate is simulated, its initial temperature appears and is usually taken as that of the adjacent cold plate. Similarly, estimated values for the initial temperatures of the (dry) SF-plate and EG coolant ring are needed when these temperatures "float."

The Operating Conditions and Controller Settings cluster shows the relevant parameters for each of the heated components in the apparatus. The initial controller output voltage ( $v c_{-}$init) and "previous" error (erro_init) are nonzero when simulating a "bumpless" startup. The maximum power to each heater element (q max) accounts for both the corresponding power supply rating and the electrical resistance in the power circuit. The HighLimit Control voltage is that used for safety purposes in the actual apparatus. Estimates for the noise amplitude in the temperature feedback signal for more critical components are based on oscilloscope monitoring of an earlier hot-plate apparatus. Default values are shown in the cluster.

The Apparatus Properties cluster values are estimated based on set-point temperatures. This assumption likely exacerbates temperature response error initially but the emphasis of the conductivity test is during the final quasi-steady phase. The surface emittances of Inconel 6 and Inconel 7 are assumed to be the same. (The thermal conductivity of the Steatite ceramic material is denoted $k_{\mathrm{st}}$.) 


\subsubsection{Numerical Output Tab}

This sheet shows the predicted temperature, controller output voltage, and set-point error for each active component during the entire simulation. "Simulated" R-Values, based on ending temperatures and heat flow and average temperatures and heat flow for the last two hours of the run, are also shown. The mean value is based on the running average for the preceding hour. The "Input" (or true) R-Value, calculated from the specimen conductivity and thickness from the Input Tab, is also shown for reference. The significant scatter in the values for the end-of-run R-Values result primarily from the noise amplitude imposed on the feedback signals.

\subsubsection{Graph Tab}

This sheet shows selected plots of the numerical output including the input and simulated $\mathrm{R}$-Value measurements. The latter values are depicted for the last two hours of the run. The latter is a key indication of whether the required temperature control and operational steadiness were achieved during the test duration.

\subsection{Suggestions for Deriving Satisfactory Controller Gain Settings}

As noted above, the simulation programs are used basically in a trial-and-error procedure. Fortunately, a test run of about a week's real-time duration can be completed with the LV programs in a few seconds.

Guidelines developed and used by the author to systematically carry out the procedure applicable to new testing conditions are described in this section.

The primary time limitation for attaining quasi-steady operation from a cold start is the relatively slow response of the meter plate. This limitation results in part from the ratio of the maximum allowable heater power to its thermal capacitance as well as heat transfer through the test specimens. Heat transfer across the meter-guard gap is intentionally small because of the low gap conductance. For the actual apparatus, a small gap temperature difference is essential to minimize thermal stress in the support structure. Consequently, initial strong swings in the inner guard-plate temperature from that of the metered section should be avoided.

The effects of progressive changes in proportional and derivative gains can be readily assessed during iterative simulations by instantly examining "before" and "after" plots. The procedure is to enter trial values on the Input Tab, display the corresponding "before" plot on the Graphs Tab, and then invoke Run for the "after" plot. This procedure is repeated until the desired control is achieved. (Another program option is to "drag" the plots of interest onto the Input Tab.)

The HP assembly is likely to require the most time to reach acceptable steady operation. Consequently, the remaining components do not have to be tuned to reach steady operation in shorter time durations.

The tuning methodology for a cold startup should focus initially on controlling the temperatures of the components in the hot-plate assembly. This assembly is also the most tedious to tune, having 4 separate heating elements that are interconnected thermally. The meter plate and connection guard are controlled to their set points: the inner guard tracks the meter plate temperature; and the outer guard tracks the inner guard. Proportional control is 
used to achieve steady operation in a reasonable time and derivative control is used to minimize excursions about the set point. Based on experiences, two scenarios on tuning the hot-plate assemble are described.

One scenario is to begin with an "old" or default set of gains, the meter-plate controller derivative gain $\kappa_{d}$ is initially reset to zero and the proportional gain $\kappa_{p}$ is adjusted for near maximum heating of the meter plat to bring its temperature up quickly to the vicinity of the set point. This approach gives a rapid initial heat up, reaching the set point in a few hours rather than days, but invariably gives a large overshoot. Derivative control is then added by increasing $\kappa_{p}$ to minimize overshoot and achieve quasi-steady operation, at least within the simulated noise band. While implementing this procedure, the controller output voltages $v_{\mathrm{c}}$ can be examined under the Numerical Output Tab to confirm that $v_{\mathrm{c}}$ is close to the maximum allowable $v_{c-h l}$ value, at least during the initial heat up phase. (The control algorithms prevent exceeding the maximum allowable current through the elements. Generally, the tuning process is iterative and must be repeated as other closely coupled components are tuned. Tight control of the inner guard is required to minimize the temperature difference across the guard gap, which simulates undesired heat flow, and avoid a systematic error in the measured R-Value. (This magnitude of this error source can be more meaningfully assessed by examining the "simulated" average vs "input" R-Value plot shown on the Graph Tab after the various components have been tuned.) The response of the inner guard plate using the "old" or default gain settings should be examined and its $\kappa_{p}$ and $\kappa_{d}$ adjusted as needed to avoid large gap temperature differences during startup as well as tight control during steady operation. The temperature values for the inner and outer guards are not shown in the HP temperature plot because they are generally indistinguishable from that of the meter plate. The set point errors, which are temperature differences, are shown for the two components in the HP set-point error plot. The tuning procedure is then applied progressively to the outer guard plate and the hot-plate connection guard.

The other scenario is to apply much more gradual heating to the meter plate and avoid a significant overshoot of its set-point temperature, i.e., use of a lower $\kappa_{p}$ and consequently a much lower $\xi_{d}$ will be required to minimize oscillation around the temperature set point.

The first scenario requires much less time to reach a steady condition but the better controller settings - proportional and derivative gains - appear to depend on the set pointinitial temperature difference. The second scenario takes much longer - up to days rather than hours - to achieve steady operation but the same controller setting appears acceptable for different setpoint - initial temperature differences. The optimum tuning procedure for the metering section, therefore, has not yet been identified.

Next, the tuning procedure is applied to the cold surface plate. Initially, its $\xi_{d}$ is set to zero, first $\kappa_{p}$, and subsequently $\kappa_{d}$ are adjusted to achieve the set-point temperature. Note that the cold surface plate actually controls the power input to the adjacent heater plate. Hence, there is a somewhat longer time lag between control feedback action and the effect on the surface plate temperature. The above tuning procedure, however, still applies. When testing with the cold plate assembly at temperatures near or below ambient and, the perimeter zone of the cold plates and cold-plate connection guards can float above their low set point even with their heating elements disabled. This situation results from an insufficient conductance from these areas to the coolant. This situation is revealed in the CP set-point errors 
plot when errors drop below set points with zero controller output. Temperature control in these two components, however, is less critical than in the hot- and inner cold-plate components for thermal conductivity measurements.

The procedure is implemented for all 10 controllers (based on symmetry), followed by iterations until the simulated temperature and "measurement" errors are within acceptable limits. The (simulated) measurement error for tuning purposes can be taken as the maximum R-value variation during the quasi-steady period provided systematic errors are also within acceptable limits. It should be noted that the former criterion can be met even in cases where subcomponents converge to steady values different from their respective set points and other systematic errors exist, such as that resulting from significant heat flow across the meter-guard gap. Examination of the R-Value plots on the Graph Tab is arguably the best indicator for establishing the validity for a set of controller gains.

\subsection{LabVIEW Program Organization and Features}

The purposes and methodologies for the main and various subprograms are discussed in this section. The intended scope is to provide enough information for a programmer familiar with LabVIEW to be able to maintain the overall programs and upgrade subVIs as needs arise.

\subsubsection{Zone Partitioning}

The metered component of the hot plate assembly has an embedded heater controlled by a standard platinum resistance thermometer (SPRT) and is isolated from the guard plate by a guard gap. It is an obvious aggregated temperature zone. The guard plate has two embedded heaters separately controlled by a thermopile across the guard gap and a ring of thermocouples near the rim. The guard is partitioned into two zones.

The cold plate SPRT controls the heater plate heating element to accomplish its setpoint temperature. The cold plate has a single embedded rim heater controlled by a ring of thermocouples near the rim to prevent temperature droop in the vicinity of its outer surface. The cold plate is thus partitioned into two zones. The partitioning diameter is taken as that to give equal thermal conductance between the controlling ring of thermocouples and the rim and the former and the partitioning diameter. That diameter is $423.2 \mathrm{~mm}$ and is also the diameter used to partition the hot plate guard plate into two zones.

The edge guard assemblies each have three embedded heating elements that are controlled based on temperatures measured by nearby thermocouples. Each assembly is subdivided into three aggregated temperature zones. The overall length of the annular-shaped part of the edge guards is $121.9 \mathrm{~mm}$ with a slot approximately $210.5 \mathrm{~mm}$ wide at the top. The thickness of the edge guard and bridge is $10 \mathrm{~mm}$. Considering the locations of the thermocouples and heating elements, the main (inner) edge guard zone is taken as $100 \mathrm{~mm}$ long. The auxiliary (outer) edge guard is then $21.9 \mathrm{~mm}$ long. The supporting "bridge" at the outer end extends an additional $118.1 \mathrm{~mm}$. This U-shaped zone is thermally connected to the auxiliary zone by a metallic conduction path approximately $114.5 \mathrm{~mm}$ wide by $10 \mathrm{~mm}$ thick.

Of all the zones described, the main and auxiliary edge guards are the least amendable for comparing measurements with simulation results based on the aggregated-capacity simplification. Although the embedded elements uniformly heat these subcomponents, thermal 
stratification inside the chamber results in temperature differences between the upper and lower parts of the guard which are not accounted for in the model. Temperatures measurements are by a single thermocouple for each zone. Its location does not necessarily give an average value for the subcomponent. For example, the temperature of the main edge guard zone is measured at the top of this subcomponent while the temperature of the adjacent auxiliary zone is measured at the bottom. Consequently, when testing at temperatures above ambient, the bottom measurement is invariably lower than at the top. The auxiliary controller reacts by increasing its heating rate to the maximum allowed, thus overheating the upper part and overheating the adjacent main subcomponent.

The additional heated zones comprise the hot and cold plate connection guards and the heater plate. The zones without heating elements, denoted "floating," comprise the block heat exchanger and several others when there is no coolant flow or residual in spiral plates or the edge-guard cooling rings. Those zones are the (empty) spiral plate, coolant clamp, and edge guard cooling rings. Unfortunately for comparing simulation and test results, temperatures of the floating components are not measured. The simulation model and, ideally, testing is based on the symmetrical mode of operation. Consequently, inboard and outboard temperatures, heat flows and controller settings are equal. With this simplification the simulation with coolant flow model comprises 10 heated zones and 2 floating zones, i.e., 12 temperature nodes. For higher test temperatures where water-jacket only cooling is used, there are 3 additional floating zones, i.e., 15 temperature nodes accounted for by the simulation model.

\subsubsection{Mathematical Model Structure}

Invoking the VI Hierarchy panel for any of the 3 versions, Fig. 1 shows the overall structure in terms of a main VI and 16 subVIs (excluding three built-in internal subprograms).

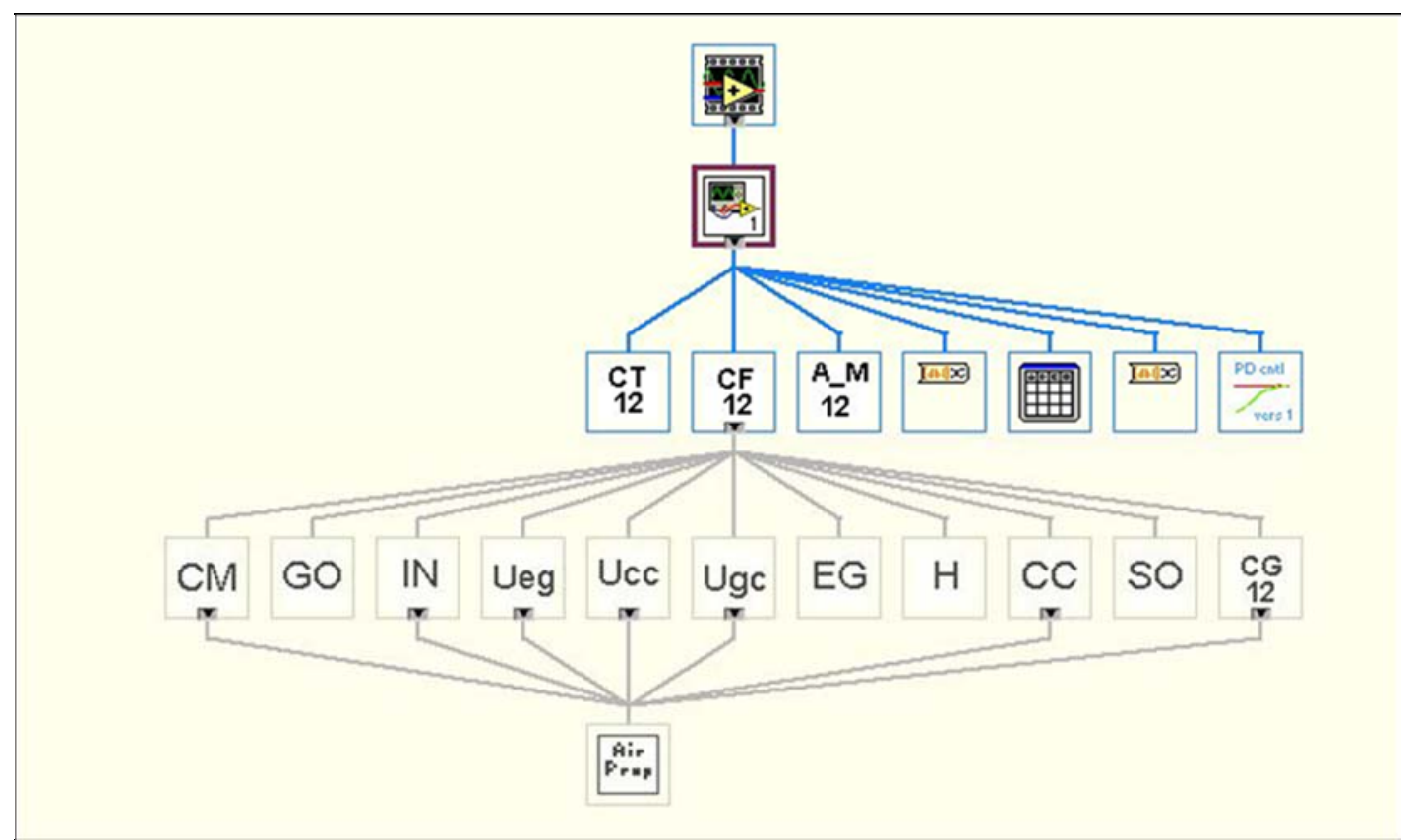

Fig. 1. Subroutine hierarchy shown for version "hp5_12"; for other versions replace the '12' with '11' or '15'. Version "hp5_15" has one additional subroutine, SubVI Cxhspcl under $\mathrm{CF}$. 
The SubVIs with numbers in the name (denoted by the suffix $\mathrm{xx}$ ) are specific to the three LabVIEW programs; the others are common. The purpose and methodology for each subVI is described as follows.

- SubVI CTxx: Thermal energy storage capacity parameters for all nodes are calculated in this subroutine. For convenience in implementing the finite-difference calculation scheme for the system depicted by Eq. (19) in Ref. [1], the capacity parameters are determined in terms of thermal capacity divided by the calculation time step, i.e., $\left(m C_{\mathrm{p}} / \Delta t\right)$ by this subVI. The specific heat depends on the material and temperature, taken as the set-point value. The masses, as shown in Table 1, were determined by weighing components.

Table 1. Component masses and heater designations.

\begin{tabular}{clcccc}
\hline No. & Component description & Symbol & $\begin{array}{c}\text { mass } \\
\text { (kg) }\end{array}$ & $\begin{array}{c}\text { Heating } \\
\text { element }\end{array}$ & $\begin{array}{c}\text { Power supply } \\
\text { rated (V, A) }\end{array}$ \\
\hline 1 & Meter plate & $\mathrm{m}$ & 4.514 & $q_{\mathrm{A}}^{\mathrm{a}}$ & 6,5 \\
2 & HP guard plate, inner & gi & 10.14 & $q_{\mathrm{M}}$ & 100,5 \\
3 & HP guard plate, outer & go & 14.35 & $q_{\mathrm{F}}$ & 55,5 \\
4 & HP connection guard & gc & 0.7456 & $q_{\mathrm{B}}$ & $36,1.5$ \\
5 & Surface plate, inner & si & 3.9728 & $\mathrm{~b}$ & \\
7 & Surface plate, outer & so & 21.245 & $q_{\mathrm{c} 9 \mathrm{a}}$ & 55,5 \\
9 & CP connection guard & $\mathrm{cc}$ & 0.862 & $q_{\mathrm{c} 13 \mathrm{a}}$ & $36,1.5$ \\
11 & Edge guard, inboard & ei & 14.31 & $q_{\mathrm{h} 3 \mathrm{a}}$ & 75,15 \\
13 & Edge guard, outboard & eo & 4.01 & $q_{\mathrm{c} 4 \mathrm{a}}$ & 55,5 \\
15 & Edge guard bridge & $\mathrm{el}$ & 13.64 & $q_{\mathrm{h} 5 \mathrm{a}}$ & 55,5 \\
17 & Block heat exchanger & $\mathrm{xh}$ & 1 & & \\
18 & Heater plate & $\mathrm{h}$ & 10.236 & $q_{\mathrm{h} 24 \mathrm{a}}$ & 150,7 \\
20 & Spiral fin plate & $\mathrm{sp}$ & 18.872 & & \\
22 & Edge guard coolant ring & $\mathrm{cr}$ & 19.783 & & \\
24 & Coolant tube clamp & $\mathrm{cl}$ & 0.294 & & \\
\hline
\end{tabular}

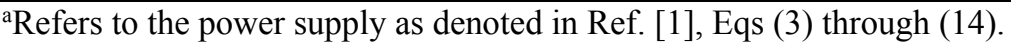

${ }^{\mathrm{b}}$ The inner zone of the surface plate has no heating element.

- SubVI CFxx: This SubVI provides the input parameters and assembles the results from ten included subVIs to estimate the conductance coefficients appearing in Eqs (3) through (17). While the methodology for formulating the various coefficients is straightforward, this subroutine is lengthy because of the large number of thermal bridges between components and convection-radiation heat transfer from component surfaces. The sub-structure is used to simply keep the parent SubVI CFxx tractable. The subVIs appearing in the parent subVI and their purposes include:

- SubVICCxx: Returns conductances associated with the hot plate connection guard. 
- SubVI CMxx: Returns conductances associated with the metering plate, SPRT, thermopile, thermocouples and heater connections, and parameters used in other CF-related SubVIs.

- SubVI GO: Returns conductances associated with meter plate outer (perimeter) guard plate.

- SubVI Hxx: Returns conductances associated with heater plate.

- SubVI IN: Returns parameters used in other CF-related SubVIs.

- SubVIEG: Returns conductances associated with edge-guard assemblies.

- SubVISO: Returns conductances associated with surface plate outer (perimeter).

- SubVIxhspcl: Returns block exchanger, spiral plate, and coolant clamp temperatures, and conductances associated with block heat exchanger. This subroutine appears only in version "hp5_15".

- SubVI Ucc: Returns overall (surface) conductance for cold plate connection guard.

- SubVI Ueg: Returns overall (surface) conductances for main and auxiliary edge guard zones.

- SubVI Ugc: Returns overall (surface) conductance for hot plate connection guard.

- SubVI CGxx: Returns conductances associated with hot-plate connection guard.

- SubVI Air Prop: Returns temperature- and pressure-dependent air properties calculated from equations in NBS Circular 564 [2]. Although this reference states that the resulting properties are for air at "low pressures," the values calculated are in error for the extremely low range of pressures that the hotplate apparatus is designed to achieve. (The transport property differences between air and nitrogen are neglected.) This subroutine can be readily replaced when more accurate property relationships for low pressure gases are available.

- In the paper [1] and this report, the symbol $C_{\mathrm{f}}$ denotes thermal conductance between subcomponents with incidental convection to the chamber gas, such as for a connecting rod. The subVIs listed above are grouped together because various convection correlations, gas and apparatus properties, and radiant transfer relationships are used in all. The symbol $U A$ denotes (overall) conductance from subcomponent surfaces to the chamber gas. The methodologies for estimating the thermal conductances are outlined in Sec. 1.5. 


\subsubsection{Heat Transfer Methods and Relationships}

The mathematical model depicts how various components and subcomponents interact with each other and the ambient gas in response to controlled heating by elements at specified locations. Consequently, it is mainly a thermal model and heat transfer principles govern the interactions. Give the intricate makeup of the apparatus, simplifications and approximations are necessary to develop a tractable model that depicts thermal response of these various elements sufficiently to examine control strategies. This section of the report describes how heat transfer principles are adapted for this goal.

\subsection{Structure}

The one-dimensional "conduction shape factor" is used when surface convection is negligible. The methodology for estimating thermal conductances from and between the various subcomponents of the guarded hot-plate apparatus is outlined. Conduction occurs through metallic connecting paths between subcomponents such as from the center of the inner and outer guard plates. Heat transfer rate is assumed one-dimensional and governed by

$$
q_{k}=-k A(r) \frac{d T}{d r}=k S_{\mathrm{k}} \Delta T
$$

Where the conduction shape factor $\left(S_{\mathrm{k}}\right)$ is evaluated from

$$
S_{\mathrm{k}}=\int \frac{d r}{A_{\mathrm{x}}(r)}
$$

\subsection{Combined Mode (Conduction-Convection-Radiation) Heat transfer}

With surface convection, such as a connecting rod (e.g., hanger or heater, thermocouple, or thermopile sheath), the thermal bridge is modeled as a thin extended surface ("fin"). Surface conductances are estimated from established free-convection correlations for plates, cylinders and annular spaces. References for such correlations are the established textbooks Incopera and DeWitt (1996) [3] and Kays and Crawford (1966) [4].

Noting that temperature differences between components and the ambient gas are relatively small, radiation heat transfer is considered as a linearized surface conductance and added to the convection conductance. The material properties are evaluated at the set temperature of the corresponding components and estimated internal gas temperature. Consequently, conductances are evaluated once and not updated as component temperatures approach steady-state values.

\subsection{Convection Correlations}

Natural convection transfer is assumed from surfaces to the surrounding gas, such as connection guards, and between surfaces in enclosures, such as from outer surfaces of plates to the enclosing edge guard. The relationship is

$$
q_{\mathrm{v}}=h_{\mathrm{v}} A_{\mathrm{s}} \Delta T
$$

The convection conductance coefficient is evaluated from 


$$
h_{\mathrm{v}}=\frac{k_{\mathrm{g}}}{L} N u_{\mathrm{L}}
$$

The Nusselt number, $N u$ L depends on the characteristic length $L$ and surface orientation.

- Vertical surfaces: Surfaces include sidewalls and cylinders. Convection correlations are in terms of Grashof number and Raleigh number. These parameters are

$$
G r_{\mathrm{L}}=\frac{g \Delta T L^{3}}{T_{\mathrm{f}} v^{2}} ; R a_{\mathrm{L}}=G r_{\mathrm{L}} P r
$$

where $T_{\mathrm{f}}$ is absolute temperature, $L$ is surface height, and $D$ is cylinder diameter.

$$
N u_{\mathrm{L}}=0.68+0.67 \frac{\left(R a_{\mathrm{L}}\right)^{\frac{1}{4}}}{\left(1+\left[\frac{0.492}{P r}\right]^{\frac{9}{16}}\right)^{\frac{4}{9}}} ; R a_{\mathrm{L}} \leq 10^{9}
$$

This correlation is also used for vertical cylinders provided $\frac{D}{L} \geq \frac{35}{G r_{L}^{1 / 4}}$; otherwise,

$$
N u_{\mathrm{d} / \mathrm{L}}=\frac{2}{\ln \left(1+\frac{2}{N u_{\mathrm{L}}}\right)}
$$

- Flat or nearly flat horizontal surfaces: These surfaces include the upper and lower surfaces of subcomponents. For flat surfaces, $L=A_{\mathrm{s}} / P$. For the upper heated surfaces use Eq. (H) and for lower heated surfaces use Eq. (I). For cylinders, use Eq. (J).

$$
\begin{aligned}
& N u_{\mathrm{L}}=0.54 R a_{\mathrm{L}}^{1 / 4} ; R a_{\mathrm{L}} \leq 10^{7} \\
& N u_{\mathrm{L}}=0.15 R a_{\mathrm{L}}^{1 / 3} ; R a_{\mathrm{L}} \geq 10^{7} \\
& N u_{\mathrm{L}}=0.27 R a_{\mathrm{L}}^{1 / 4} ; R a_{\mathrm{L}} \leq 10^{7} \\
& N u_{\mathrm{L}}=0.15 R a_{\mathrm{L}}^{1 / 3} ; R a_{\mathrm{L}} \geq 10^{7}
\end{aligned}
$$




$$
N u_{\mathrm{D}}=\left\{0.60+\frac{0.387 R a_{\mathrm{D}}^{1 / 6}}{\left[1+(0.559 / P r)^{9 / 16}\right]^{8 / 27}}\right\}^{2} ; R a_{\mathrm{D}} \leq 10^{12}
$$

- Horizontal annular enclosure: The gap between the hot and cold plate assemblies and the surrounding edge guard is modeled as an annulus for estimating convection heat transfer between the two surfaces. This conductance is based on

$$
q_{\mathrm{v}}=\frac{2 \pi k_{\mathrm{eff}}}{\ln \left(\frac{d_{\mathrm{o}}}{d_{\mathrm{i}}}\right)} \Delta T=C_{\mathrm{f}} \Delta T
$$

where

$$
\begin{aligned}
& k_{\mathrm{eff}}=0.386 k_{\mathrm{g}}\left(\frac{P r}{0.861+P r}\right)^{1 / 4}\left(R a_{\mathrm{c}}^{*}\right)^{1 / 4} ; \\
& R a_{\mathrm{c}}^{*}=\frac{\ln \left[\left(d_{\mathrm{o}} / d_{\mathrm{i}}\right)\right]^{4}}{L^{3}\left(d_{\mathrm{i}}^{-3 / 5}+d_{\mathrm{o}}^{-3 / 5}\right)} R a_{\mathrm{L}} \\
& R a_{\mathrm{L}}=\frac{g \Delta T L^{3}}{T_{\mathrm{f}} v^{2}}
\end{aligned}
$$

- Surface radiation: Radiation heat transfer between subcomponent surfaces and the enclosing chamber is estimated using

$$
q_{\mathrm{r}}=\varepsilon \sigma A_{\mathrm{s}}\left[T_{\mathrm{s}}^{4}-T_{\mathrm{v}}^{4}\right] \approx 4 \varepsilon \sigma A_{\mathrm{s}} T_{\mathrm{sp}}^{3}\left[T_{\mathrm{s}}-T_{\mathrm{v}}\right]
$$

The set point temperatures are in absolute units.

Heat transfer for one subcomponent surface 1 to another component surface 2, such as outer surfaces of plate assemblies to the enclosing edge guard is determined by

$$
q_{\mathrm{r}}=\sigma A_{1} F_{1-2}\left[T_{\mathrm{sp} 1}^{2}+T_{\mathrm{sp} 2}^{2}\right]\left[T_{\mathrm{sp} 1}+T_{\mathrm{sp} 2}\right]\left[T_{1}-T_{2}\right]
$$

(The radiation shape factor $F_{1-2}=1$ for this case.)

\subsection{Extended Surfaces}

The references in Sec. 1.4.2.1.3 also give the relevant relationships for thin extended surfaces ("fins"), infinitely long or of finite length with adiabatic, convective, or prescribed 
temperature tips. The latter is used for a rod (sheath, tube, or SPRT well) connecting two components with prescribed temperatures.

- "Indefinite" Height: These surfaces also include cylinders that are modeled as infinitely long fins. The convection coefficient $h_{\mathrm{v}}$ is estimated by taking $L$ as $10 \mathrm{~mm}$ and using $(\mathrm{F})$. Heat transfer from the surface to the surrounding gas is

$$
q_{\mathrm{v}}=\sqrt{h_{\mathrm{v}} P k A_{\mathrm{x}}} \Delta T=C_{\mathrm{f}} \Delta T
$$

where the criterion for modeling as a long fin is

$$
\left(\sqrt{\frac{h_{\mathrm{v}} P}{k A_{\mathrm{x}}}}\right) L=m L \geq 5
$$

- Extended Surface, Specified Base and Tip Temperatures $\left(T_{\mathrm{b}}, T_{\mathrm{L}}\right)$ in Ambient at $T_{\mathrm{a}}$ : Rods and tubes connecting components at different temperatures are modeled as fins with specified tip temperatures. Heat transfer is by surface conductance to the ambient gas and conduction between the two components. The relationship for this configuration is given by

$$
q_{\mathrm{v}}=\sqrt{h P k A_{\mathrm{x}}}\left\{\left[T_{\mathrm{b}}-T_{\mathrm{a}}\right]\left(\frac{\cosh (m L)-1}{\sinh (m L)}\right)+\left[T_{\mathrm{b}}-T_{\mathrm{L}}\right]\left(\frac{1}{\sinh (m L)}\right)\right\}
$$

where $T_{\mathrm{a}}$ is the temperature of the ambient gas (air) and $T_{\mathrm{b}}, T_{\mathrm{L}}$ are temperatures of the two components. The surface conductance $h$ accounts for convection and radiation. The first term inside the larger brackets accounts for heat transfer to the ambient and the second term is for conduction between the two components.

\subsection{Combined Mode Conductance Summary}

Table 2 summarizes conductances, estimation methodologies, and shows typical magnitudes for hot-plate testing near room temperature. The identifying subscripts shown in Table 2 correspond to the conductances denoted $C_{\mathrm{xx}-\mathrm{yy}}$ in Eqs (3) through (17) in Ref. [1]. This summary is for version hp5-12. For summaries based on other operating conditions and also for versions hp5-11 and hp5-15, the tabulations are shown under the "Debug" tab of the respective LabVIEW programs. 
Table 2. Description, evaluation basis, and typical values of conductances between various subcomponents.

\begin{tabular}{|c|c|c|c|c|}
\hline No. & Subscript & $\begin{array}{l}\text { Conductance } \\
\text { description }\end{array}$ & Evaluation basis & $\begin{array}{l}\text { Value }^{\mathrm{a}} \\
\text { (W/K) }\end{array}$ \\
\hline 1 & mgi & $\begin{array}{l}\text { Gap between meter plate and } \\
\text { guard ring }\end{array}$ & $\begin{array}{l}\text { Parallel conduction: Waspaloy }{ }^{\mathrm{TM}} \text { hangers, } \\
\text { sheathed SPRT and Inconel } 750^{\mathrm{TM}} \text { well, } \\
\text { sheathed TP leads, and air in diamond- } \\
\text { shaped gap }\end{array}$ & 0.276306 \\
\hline 2 & msi & Across test specimen & $\left(\mathrm{kA}_{\mathrm{s}, \mathrm{m}} / \mathrm{L}\right)_{\mathrm{ta}}$ & 0.017839 \\
\hline 3 & gio & $\begin{array}{l}\text { Inner to outer guard ring } \\
\text { zones }\end{array}$ & Conduction shape factor $\left(\mathrm{k}_{\mathrm{Ni}} \mathrm{S}_{\mathrm{k}}\right)_{\text {guard }}$ & 22.53049 \\
\hline 4 & gisi & Across test specimen & $\mathrm{k}_{\mathrm{t}} \mathrm{A}_{\mathrm{s}, \mathrm{gi}} / \mathrm{L}_{\mathrm{t}}$ & 0.03875 \\
\hline 5 & $\operatorname{gogc}$ & $\begin{array}{l}\text { Outer guard ring to ring- } \\
\text { guard connection }\end{array}$ & $\begin{array}{l}3 \text { Waspaloy }{ }^{\mathrm{TM}} \text { hangers; sheathed thermo- } \\
\text { piles, thermocouple, and heater leads; } \\
\text { SPRT and well }\end{array}$ & 0.189253 \\
\hline 6 & goso & Across test specimen & $\mathrm{k}_{\mathrm{ta}} \mathrm{A}_{\mathrm{s} . \mathrm{go}} / \mathrm{L}_{\mathrm{ta}}$ & 0.054655 \\
\hline 7 & goei & $\begin{array}{l}\text { Outer guard ring to inboard } \\
\text { edge guard }\end{array}$ & $\begin{array}{l}\text { Free convection and radiation across } 10 \\
\text { mm gap }\end{array}$ & 0.053555 \\
\hline 8 & gcxh & $\begin{array}{l}\text { Ring connection guard to } \\
\text { block heat exchanger }\end{array}$ & $\begin{array}{l}\text { Two hangers; sheathed thermocouple, ther- } \\
\text { mopile, and heater leads; and SPRT with } \\
\text { well }\end{array}$ & 0.143797 \\
\hline 9 & $\operatorname{gccc}$ & $\begin{array}{l}\text { Ring connection to cold-plate } \\
\text { connection guard }\end{array}$ & $\begin{array}{l}\text { Convection and radiation across gap (ne- } \\
\text { glected) }\end{array}$ & 0 \\
\hline 10 & sio & $\begin{array}{l}\text { Inner to outer surface plate } \\
\text { zones }\end{array}$ & Conduction shape factor $\left(\mathrm{k}_{\mathrm{Ni}} \mathrm{S}_{\mathrm{k}}\right)_{\text {surf } \mathrm{pl}}$ & 8.7072 \\
\hline 11 & $\operatorname{sih}$ & $\begin{array}{l}\text { Inner surface-plate zone to } \\
\text { heater plate }\end{array}$ & $\begin{array}{l}\text { Series conduction across } 1 / 2 \text { surface plate, } \\
0.8 \mathrm{~mm} \text { thick fabric insulation, and } 1 / 2 \\
\text { heater plate }\end{array}$ & 18.36921 \\
\hline 12 & socc & $\begin{array}{l}\text { Outer surf. pl zone to cold- } \\
\text { plate connection guard }\end{array}$ & $\begin{array}{l}\text { Parallel conduction: } 2 \text { hangers, SPRT as- } \\
\text { sembly, and sheathed thermocouples (5) } \\
\text { and heater leads ( } 2 \text { ) }\end{array}$ & 0.110391 \\
\hline 13 & soei & $\begin{array}{l}\text { Outer surf. pl zone to inboard } \\
\text { edge guard }\end{array}$ & Same as 12 & 0.08856 \\
\hline 14 & soh & $\begin{array}{l}\text { Outer surf. pl zone to heater } \\
\text { plate }\end{array}$ & $\begin{array}{l}\text { Series conduction across } 1 / 2 \text { surface plate, } \\
0.8 \mathrm{~mm} \text { tk fabric insulation parallel with } \\
6 \# 6 \text { Iconel } 600^{\mathrm{TM}} \text { screws, and } 1 / 2 \text { heater } \\
\text { plate }\end{array}$ & 97.3925 \\
\hline 15 & ccei & $\begin{array}{l}\text { Cold-plate connection guard } \\
\text { to inboard edge guard }\end{array}$ & $\begin{array}{l}\text { Convection and radiation across gap (ne- } \\
\text { glected) }\end{array}$ & 0 \\
\hline 16 & ccec & $\begin{array}{l}\text { Cold-plate conn. guard to } \\
\text { back-plate coolant }\end{array}$ & $\begin{array}{l}\text { Conduction along } 4 \# 10 \text { Inconel } 600^{\mathrm{TM}} \\
\text { bolts }\end{array}$ & 0.0441 \\
\hline 17 & cch & $\begin{array}{l}\text { Cold-plate conn. guard to } \\
\text { heater plate }\end{array}$ & Convection from wells, sheaths and wires & 0.01089 \\
\hline 18 & hei & $\begin{array}{l}\text { Heater plate to inboard edge } \\
\text { guard }\end{array}$ & $\begin{array}{l}\text { Free convection and radiation across } 10 \\
\text { mm gap }\end{array}$ & 0.037953 \\
\hline 19 & heo & $\begin{array}{l}\text { Heater plate to outboard edge } \\
\text { guard }\end{array}$ & $\begin{array}{l}\text { Free convection and radiation across } 10 \\
\text { mm gap (neglected) }\end{array}$ & 0 \\
\hline 20 & eio & $\begin{array}{l}\text { Inboard to outboard edge } \\
\text { guard zones }\end{array}$ & Conduction shape factor $\left(\mathrm{k}_{\mathrm{Ni}} \mathrm{S}_{\mathrm{k}}\right)_{\text {edge guard }}$ & 24.778 \\
\hline \multicolumn{5}{|c|}{ Conductances with convective component ${ }^{b}$} \\
\hline 1 & goengc & $\begin{array}{l}\text { Hot plate outer guard ring to } \\
\text { connection guard }\end{array}$ & Convection from wells, sheaths and wires & 0.0071352 \\
\hline
\end{tabular}




\begin{tabular}{|c|c|c|c|c|}
\hline No. & Subscript & $\begin{array}{c}\text { Conductance } \\
\text { description }\end{array}$ & Evaluation basis & $\begin{array}{l}\text { Value }^{\mathrm{a}} \\
\text { (W/K) }\end{array}$ \\
\hline 2 & gcvpxh & $\begin{array}{l}\text { Connection guard to block } \\
\text { heat exchanger }\end{array}$ & Convection from wells, sheaths and wires & 0.0075405 \\
\hline 3 & gxhvpspc & $\begin{array}{l}\text { Block heat exchanger to spi- } \\
\text { ral plate coolant clamp }\end{array}$ & (Strap disconnected at present) & 0 \\
\hline 4 & soencc & $\begin{array}{l}\text { Surface plate to connection } \\
\text { guard }\end{array}$ & Convection from wells, sheaths and wires & 0.0041517 \\
\hline 5 & ccenspc & $\begin{array}{l}\text { Connection guard to spiral } \\
\text { plate coolant clamp }\end{array}$ & Convection from wells, sheaths and wires & 0.0078175 \\
\hline 6 & ccenh & $\begin{array}{l}\text { Connection guard to heater } \\
\text { plate }\end{array}$ & Convection from wells, sheaths and wires & 0.0006416 \\
\hline \multicolumn{5}{|c|}{ Surface Coefficients } \\
\hline 1 & $\mathrm{gc}$ & $\begin{array}{l}\text { Surface } U A_{\mathrm{s}} \text {, ring connection } \\
\quad \text { guard to ambient gas at } T_{\mathrm{vp}}\end{array}$ & $\begin{array}{l}\text { Free convection (vertical surface) and ra- } \\
\text { diation to ambient at } T_{\mathrm{vp}}\end{array}$ & 0.106054 \\
\hline 2 & $\mathrm{cc}$ & $\begin{array}{l}\text { Surface } U A_{\mathrm{s}} \text {, cold-plate con- } \\
\text { nection guard to ambient } \\
\text { gas }\end{array}$ & Same as 1 & 0.109124 \\
\hline 3 & ei & $\begin{array}{l}\text { Surface } U A_{\mathrm{s}}, \text { inner edge } \\
\text { guard to ambient gas }\end{array}$ & $\begin{array}{l}\text { Free convection (vertical surface) and ra- } \\
\quad \text { diation to ambient at } T_{\mathrm{vp}}\end{array}$ & 0.109124 \\
\hline 4 & eo & $\begin{array}{l}\text { Surface } U A_{\mathrm{s}} \text {, outer edge } \\
\text { guard to ambient gas }\end{array}$ & & \\
\hline 5 & el & $\begin{array}{l}\text { Surface } U A_{\mathrm{s}} \text {, edge-guard } \\
\text { bridge surface to ambient } \\
\text { gas }\end{array}$ & $\begin{array}{l}\text { Conduction through micro porous insula- } \\
\text { tion }\end{array}$ & 0.069368 \\
\hline 6 & $\mathrm{xh}$ & $\begin{array}{l}\text { Surface } U A_{\mathrm{s}} \text {, block heat ex- } \\
\text { changer surface to ambient } \\
\text { gas }\end{array}$ & $\begin{array}{l}\text { Free convection (vertical surface) and ra- } \\
\quad \text { diation to ambient at } T_{\mathrm{vp}}\end{array}$ & 0.943321 \\
\hline
\end{tabular}

${ }^{a}$ Values based on material properties at approximately $300 \mathrm{~K}$, dry air at $298 \mathrm{~K}$ and $101.325 \mathrm{kPa}$ in the chamber. The test material taken as $R_{\mathrm{M}}=1.761 \mathrm{~m}^{2} \cdot \mathrm{K} / \mathrm{W}, 50.8 \mathrm{~mm}$ thick.

${ }^{\mathrm{b}}$ Conductances in this section (i.e., with en or vp between the two subcomponents) account for convection to the enclosure gas (en) or chamber (vp) along connecting thermal bridges (such as thermocouple or heater sheaths).

- SubVI $a \_m x x$ : This subroutine forms the coefficient matrix for solving the set of simultaneous equations for the component temperatures at each time step in the simulation. These coefficients, depicted in the left side of Eq. 19 [Thomas and Zarr (2018)], comprise combinations of thermal conductances between components, thermal capacitances of components, and fixed temperatures (such as that for chamber air, coolant, etc). The inputs are generally passed into the subprogram as onedimensional arrays and the output is a two-dimensional array.

- SubVI PD Cntl: The purpose of this subroutine is to implement incremental proportional-derivative temperature control by updating the voltage outputs of the various programmable power supplies to their connected heating elements.

Table 3 shows the rated voltage and current for the heating symbols shown in Eqs $2-12$. (Identical power supplies for the opposite side are not listed). The maximum power supplied to heating elements, required input for the LV program, is either current or voltage limited. If voltage limited, it can depend significantly on the heating element resistance, especially at higher test temperatures, and will be less than the products of the voltages-currents in Table 3. In this case, the maximum power 
supplied to the heating element is $\left(V_{\text {rated }} / R_{\mathrm{L}}\right)^{2}\left(R_{\text {elt }}\right)$ where $R_{\mathrm{L}}$ and $R_{\text {elt }}$ are the total circuit and element resistances, which depend on element temperature. The maximum power for voltage limited supplies can be calculated from the stand-alone SubVI qmax T and entered on the input tab of the program. As an example, $q_{\max }$ for a power supply rated at $200 \mathrm{~V}$ and 7 amperes (1400 volt-amps) drops to $844 \mathrm{~W}$ at an element temperature of $175 \mathrm{C}$.

The control algorithm, Eqs (17) through (19) in Ref [1], are accomplished in this SubVI. In the simulation algorithm, the heating currents are limited from the rated values as show in the tabulated values entered on the LabVIEW input tab. In the actual apparatus, the current limits are set on the respective power supplies.

Table 3. Heater element power supplies.

\begin{tabular}{lll}
\hline \multicolumn{1}{c}{ Heater element location } & Symbol & $\begin{array}{c}\text { Rated voltage } \\
\text { and current }\end{array}$ \\
\hline Meter plate & $q_{\mathrm{A}}, q_{\mathrm{E}}$ & 6,5 or 55,5 \\
Guard plate inner & $q_{\mathrm{M}}$ & 100,5 \\
Guard plate outer (rim) & $q_{\mathrm{F}}$ & 55,5 \\
Meter plate conn. guard & $q_{\mathrm{B}}$ & $36,1.5$ \\
Surface pl. outer (rim) & $q_{\mathrm{G}}$ & 55,5 \\
Cold plate connection. guard & $q_{\mathrm{C}}$ & $36,1.5$ \\
Heater plate & $q_{\mathrm{P}}$ & $36,1.5$ \\
\hline
\end{tabular}

\section{References}

[1] Thomas WC, Zarr RR (2018) Transient Thermal Response of a Guarded-Hot-Plate Apparatus for Operation Over an Extended Temperature Range. J Res Natl Inst Stan 123:123001. https://doi.org/10.6028/jres.123.001.

[2] Hilsenrath J, Beckett CW, Benedict WS, Fano L, Hoge HJ, Masi JF, Nuffal RL, Touloukian YS, Woolley HW (1955), Table of the thermal properties of gases, National Bureau of Standards Circular 564, Washington, DC.

[3] Incopera FP, DeWitt DP (1996) Fundamentals of Heat and Mass Transfer (John Wiley and Sons), 4th Ed.

[4] Kays WM, Crawford ME (1966) Convective Heat and Mass Transfer (McGraw Hill), 3rd Ed. 